\title{
ADSORÇÃO DE CORANTE CATIÔNICO POR CARVÃo ATIVADO DE CASCA DE BANANA
}

\author{
A. M. BUGIERECK ${ }^{1}$, S. M. BEHLING ${ }^{1}$, M. A. FIORI ${ }^{1,2}$, J. M. M. de MELLO ${ }^{1,2}$, G. \\ L.COLPANI $^{1}$, J. D. MAGRO ${ }^{1,2}$ \\ ${ }^{1}$ Universidade Comunitária da Região de Chapecó, Programa de Pós-Graduação em \\ Tecnologia e Gestão da Inovação \\ 2 Universidade Comunitária da Região de Chapecó, Programa de Pós-Graduação em Ciências \\ Ambientais \\ E-mail para contato: alexandrambugiereck@ unochapeco.edu.br
}

\begin{abstract}
RESUMO - O desenvolvimento industrial tem aumentado de forma agressiva o número de contaminantes químicos em cursos hídricos. A busca por adsorventes alternativos com baixa toxicidade e de baixo custo tem se intensificado nos últimos anos. Neste trabalho o carvão ativado foi produzido a partir da casca de banana, sendo avaliada a sua eficiência como precursor de um adsorvente para a remoção do azul de metileno. O carvão foi preparado por duas rotas distintas, a ativação química, com uma solução aquosa de ácido fosfórico $1: 1$ e carbonização por 2 horas a $600{ }^{\circ} \mathrm{C}$, e somente a carbonização por 2 horas a $400{ }^{\circ} \mathrm{C}$. As cinéticas demonstraram que o modelo de pseudossegunda ordem adequou-se aos dados experimentais por apresentar a menor difrença entre a quantidade adsorvida calculada e a experimental. A amostra submetida à ativação química apresentou uma capacidade adsortiva no equilíbrio de $6,89 \mathrm{mg} \cdot \mathrm{g}^{-1}$, enquanto a amostra carbonizada atingiu $8,36 \mathrm{mg} \cdot \mathrm{g}^{-1}$.A isoterma de Freundlich apresentou melhor ajuste aos dados para a amostra ativada, coma constante $\mathrm{K}_{\mathrm{F}}=107,168\left(\left(\mathrm{mg} \cdot \mathrm{g}^{-1}\right) \cdot\left(\mathrm{L}_{\mathrm{mg}} \mathrm{mg}^{-1}\right)^{1 / \mathrm{n}}\right)$, enquanto a isoterma de Langmuir representou melhor a amostra somente carbonizada, com $\mathrm{K}=0,038 \mathrm{~L} \cdot \mathrm{mg}^{-1}$. Os resultados demonstraram que os carvões obtidos com ambas as rotas avaliadas são eficientes na remoção de corantes catiônicos.
\end{abstract}

\section{INTRODUÇÃO}

O crescimento econômico tem proporcionado à sociedade, bens de suma importância, tais como os alimentícios, de materiais e serviços. Em sentido oposto, costuma-se apontar em especial a atividade industrial como causa da degradação ambiental, sendo um dos temas que mais gera custos ao estado, e da mesma maneira preocupa as empresas atuantes no setor industrial (Aguiar $e$ al., 2002).

A remoção da cor dos efluentes é um dos grandes problemas enfrentados pelo setor têxtil. A elevada estabilidade biológica dos corantes dificulta sua degradação pelos sistemas de tratamento convencionais empregados pelas indústrias têxteis (Dallago e Smaniotto, 2005). As substâncias corantes contribuem significativamente para a poluição de recursos hídricos por dificultarem a penetração dos raios solares, prejudicando o metabolismo fotossintético de algumas 
espécies; além disso, apresentam-se como recalcitrantes e potencialmente cancerígenos (Freire e Freitas, 2010).

O processo de adsorção envolve a transferência de massa de uma fase fluida para a superfície de um sólido, essa técnica de tratamento de efluentes vem sendo amplamente estudada por apresentar elevada eficiência e por ser economicamente viável no tratamento de efluentes. A utilização de materiais de baixo custo na fabricação do carvão ativado é uma alternativa para a utilização de rejeitos industriais alimentícios, que normalmente são descartados e acabam perdendo seu valor (Juchen et al, 2013).

A banana é a segunda fruta mais produzida no Brasil, porém, a sua casca geralmente é descartada, ou em alguns casos, é utilizada na alimentação de animais ou eventualmente em compostagem, o uso destes resíduos permitiria a redução da poluição ambiental, agregando valor à cultura da banana (Bakry et al., 1997; Embrapa, 2012).

Desta forma, este trabalho apresenta resultados de estudos que confirmam a viabilidade da aplicação da casca de banana para produção de carvão ativado e sua aplicação como material adsorvente. $\mathrm{O}$ trabalho emprega duas rotas para a obtenção do adsorvente, empregando numa o ácido fosfórico para a ativação química e na outra somente carbonização.

\section{MATERIAL E MÉTODOS}

\subsection{Preparação das amostras}

As cascas da banana in natura, que foram adquiridas no comércio local da cidade de Chapecó-SC, foram higienizadas, sendo posteriormente picadas e secas em um desidratador por 24 horas em temperatura de $60{ }^{\circ} \mathrm{C}$. Após a secagem as cascas foram trituradas e peneiradas até granulometria menor que $0,6 \mathrm{~mm}$. A farinha obtida, denominada por MP, foi armazenada sob refrigeração.

A MP foi submetida ao processo de ativação química com ácido fosfórico 1:1 por 1 hora (amostra $\mathrm{C} 1$ ), seca a $100^{\circ} \mathrm{C}$ em estufa e submetida à carbonização em mufla à atmosfera ambiente por 2 horas a $600{ }^{\circ} \mathrm{C}$ com taxa de aquecimento de $10^{\circ} \mathrm{C} \cdot \mathrm{min}^{-1}$. Uma segunda amostra da MP foi carbonizada a $400{ }^{\circ} \mathrm{C}$ por 2 horas (amostra $\mathrm{C} 2$ ), sem o tratamento químico por solução ácida e de acordo com as metodologias testadas por Colpani (2012). Após carbonização a amostra $\mathrm{C} 1$ foi submetida à lavagem com uma solução de bicarbonato de sódio $1 \%$ a $80{ }^{\circ} \mathrm{C}$ até a neutralização do $\mathrm{pH}$, após foi seca a $100{ }^{\circ} \mathrm{C}$ em estufa até a sua massa permanecer constante. $\mathrm{O}$ carvão seco obtido foi macerado até apresentar-se como um pó fino.

\subsection{Ensaios de cinética e Isoterma}

Os estudos da cinética de adsorção foram realizados em batelada, utilizando-se $1 \mathrm{~g}$ de amostra de cada carvão em $500 \mathrm{~mL}$ de solução contendo $15 \mathrm{mg} \cdot \mathrm{L}^{-1}$ do corante azul de metileno em temperatura de $20{ }^{\circ} \mathrm{C}$, sob constante agitação. A cada 5 minutos da primeira hora foram coletadas alíquotas da solução para medidas de concentração, sendo na sequência retiradas a cada meia hora até que o equilíbrio fosse atingido. A análise da concentração do corante azul de metileno na solução foi realizada no comprimento de onde de $665 \mathrm{~nm}$ em um espectrofotômetro UV-Visível (modelo SP 220, marca Bioespectro). 
As amostras foram submetidas a análises de adsorção no equilíbrio para obtenção de isotermas. Foi preparada uma solução de azul de metileno com $100 \mathrm{mg} . \mathrm{L}^{-1}$, a qual foi transferida a 8 erlenmeyers, contendo $300 \mathrm{ml}$ cada. Foram pesadas oito amostras de massa igual a $0,05 \mathrm{~g}$ à 0,4 $\mathrm{g}$, com variação de $0,05 \mathrm{~g}$, e estas colocadas nos erlemeyers. As amostras tiveram seu pH inicial avaliado e foram submetidas a agitação por 5 hem um shaker (modelo DST 01, marca Dist). Após a agitação e o equilíbrio atingido, foram recolhidos $5 \mathrm{~mL}$ de cada amostra, em triplicata,os quais foram submetidos a centrifugação por 7 minutos à $3600 \mathrm{rpm}$. Na sequência, as alíquotas foram quantificadas mediante a leitura da absorbância em $665 \mathrm{~nm}$ no espectrofotometro UV-Visível.

\subsection{Análise morfológica}

A morfologia dos materiais obtidos, amostras $\mathrm{C} 1$ e $\mathrm{C} 2$, foram caracterizadas através da microscopia eletrônica de varredura (MEV). As análises de microscopia eletrônica foram realizadas no Laboratório Central de Microscopia Eletrônica (LCME) da Universidade Federal de Santa Catarina, utilizando o equipamento JEOL JSM-6390LV. No intuito de avaliar as alterações das estruturas devido aos diferentes parâmetros empregados, foram geradas microfotografias do material. O material em pó, previamente seco foi aderido a um suporte metálico (stub), com fita de carbono e recoberto com um filme de ouro, devido características isolantes do carvão. As ampliações aplicadas foram de 5000 vezes.

\section{RESULTADOS E DISCUSSÃO}

\subsection{Análise morfológica}

As micrografias foram obtidas para as amostras geradas nos processos com e sem ativação ácida. A Figura 1 apresenta as imagens de MEV para amostras de MP (a), amostras apenas carbonizadas (b) e amostras ativadas por ácido fosfórico (c).

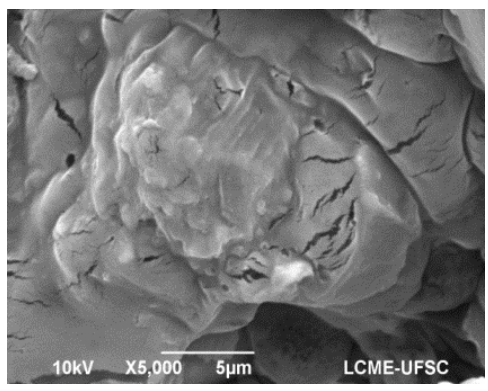

(a)

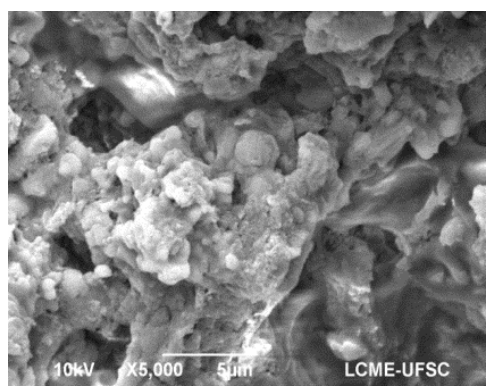

(b)

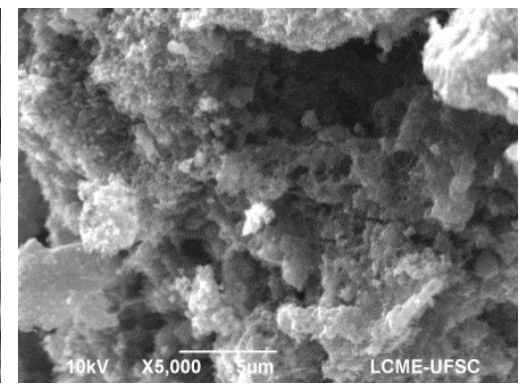

(c)

Figura 1-Micrografias de MEV com ampliação de 5.000 vezes para (a) MP, (b) amostra somente carbonizada - C2 - e (c) amostra ativada e carbonizada-C1.

Foi observado um aumento da densidade dos poros após o processo de ativação do carvão (C1), quando comparado à matéria-prima (MP), sendo notado que o tratamento ácido gerou poros menores e bem distribuídos por toda a superfície do carvão, isso ocorre devido à agressividade do ácido fosfórico e também pela ação deste que atua como um catalisador para promover a ruptura de ligações aril-éter, formando ésteres fosfóricos pela ligação do agente ativador com os grupos hidroxila da lignina na superfície do material precursor do carvão ativado. Estas reações provocam 
o afastamento das cadeias e geram a expansão da estrutura e a redistribuição dos carbonos remanescentes, ocorrendo a posterior polimerização destes grupos fosfatos com o aumento de temperatura, aumentando o volume de mesoporos. Após a remoção do ácido, a matriz apresentará um estado expandido com uma estrutura de poros disponíveis para os fenômenos de adsorção (Nahil, 2012).

A amostra C2, também apresenta porosidade superior à MP, pois conforme Clark (2010) uma vez que a carbonização causa a volatilização de compostos voláteis e gases leves, uma estrutura porosa primária será originada.

\subsection{Cinética de adsorção}

As cinéticas de adsorção foram estudadas no intuito de compreender o mecanismo que rege os fenômenos de adsorção nos carvões obtidos. Na análise cinética, os resultados foram ajustados pelos modelos de cinética de pseudo-primeira ordem e pseudossegunda ordem.

Na Figura 2 estão apresentadas as dependências da concentração do corante na solução em função do tempo para as amostras C1 e C2.
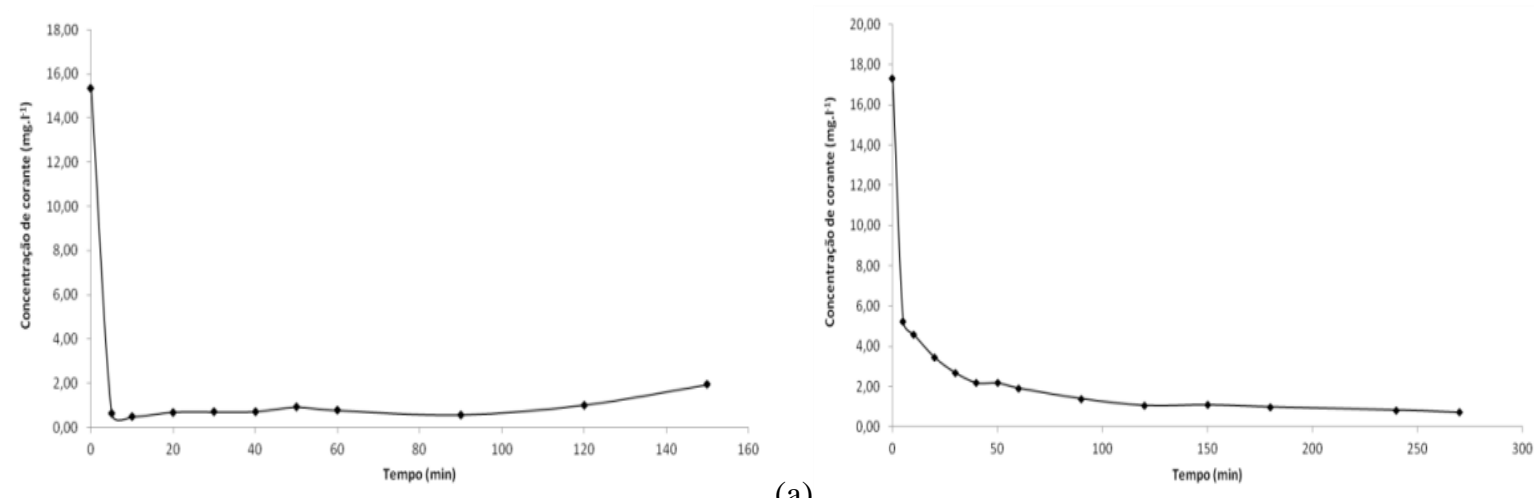

(a)

(b)

Figura 2 - Concentração de corante na solução em função do tempo. (a) com carvão ativado com ácido fosfórico 1:1 por 1 hora (amostra C1) e (b) carvão apenas carbonizado a $400^{\circ} \mathrm{C}$ por 2 horas (amostra C2).

Como pode ser visto na Figura 2, para $\mathrm{C} 1$ a remoção de corante ocorreu com eficiência de aproximadamente $98 \%$ em apenas $20 \mathrm{~min}$, com uma pequena oscilação posterior devido a fraca dessorção em função de variações no pH, pois conforme Annadurai et al. (2002) este precursor sofre efeito significativo na adsorção do corante azul de metileno devido mudanças no pH.A amostra C2, por sua vez,apresentou aproximadamente $96 \%$ de eficiência na remoção do corante, atingindo o equilíbrio após 270 minutos.

As linearizações da relação entre a concentração e o tempo são apresentadas nas Figuras 3 e 4, representando respectivamente os modelos de pseudo-primeira e pseudossegunda ordem. Conforme observado nos resultados dos modelos cinéticos propostos, os dados experimentais obtidos apresentaram melhor ajuste ao modelo de pseudossegunda ordem. 


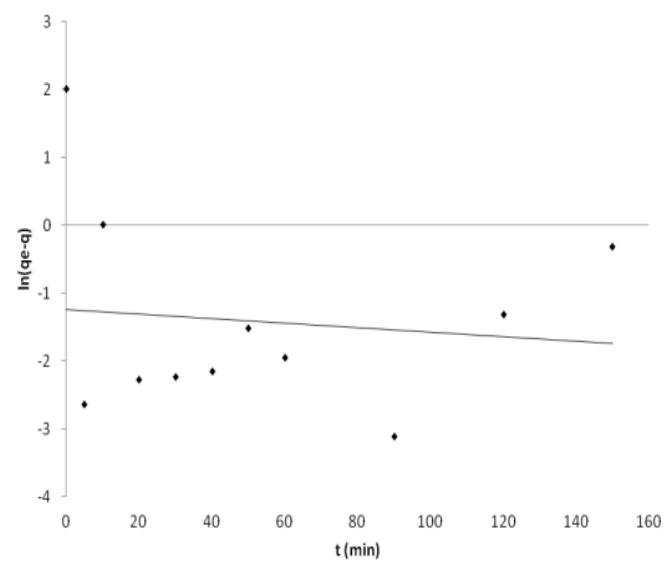

(a)

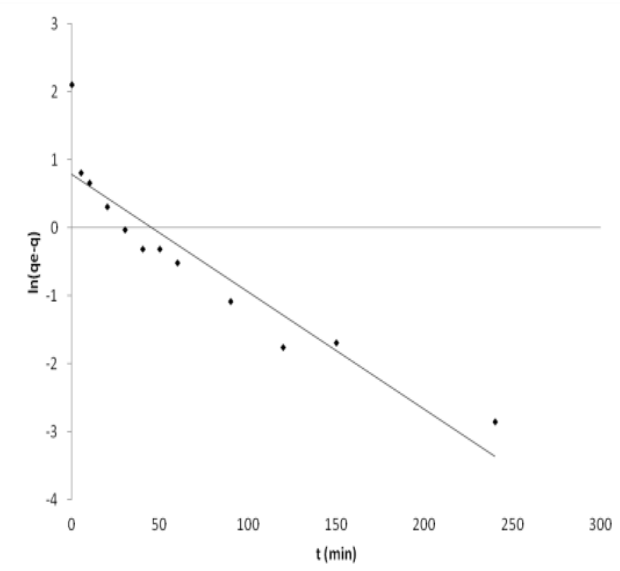

(b)

Figura 3 - Linearizações para o modelo de pseudo-primeira ordem, (a) resultados obtidos com carvão ativado com ácido fosfórico 1:1 por 1 hora e (b) com carvão somente carbonizado a $400^{\circ} \mathrm{C}$ por 2 horas.

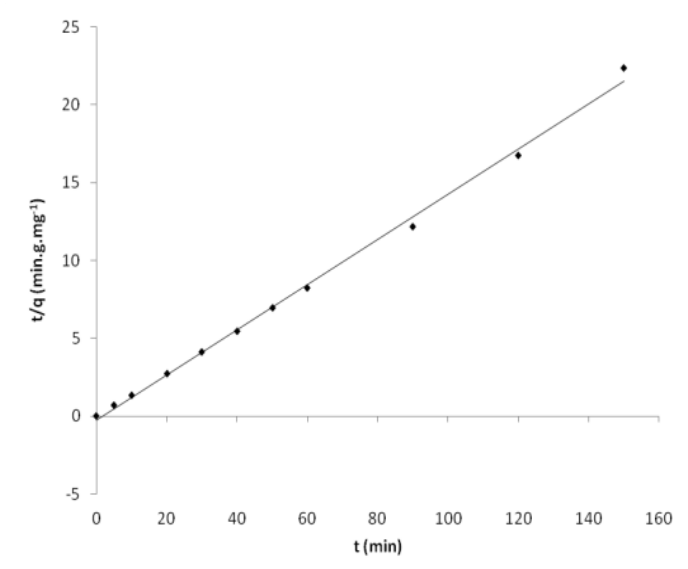
carvão ativação com ácido fosfórico 1:1 por 1 hora e (b) com carvão somente carbonizado a $400^{\circ} \mathrm{C}$.

A avaliação de ajuste estatístico dos modelos foi realizada pela comparação dos coeficientes de determinação $\left(\mathrm{R}^{2}\right)$, e pelos valores de $\mathrm{q}_{\mathrm{e}}$ calculados com o ajuste dos modelos e de $\mathrm{q}_{\mathrm{e}}$ obtidos a partir dos resultados experimentais, para os modelos de pseudo-primeira e pseudossegunda ordem. A amostra $\mathrm{C} 2$ obteve um qe igual a $8,30 \mathrm{mg} \cdot \mathrm{g}^{-1}$, muito próximo ao calculado $\left(\mathrm{q}_{\mathrm{e} \text { calc }}=8,36 \mathrm{mg} \cdot \mathrm{g}^{-1}\right)$. Para a amostra $\mathrm{C} 1$ obteve-se experimentalmente um $\mathrm{q}_{\mathrm{e}}$ com valor de $7,43 \mathrm{mg} \cdot \mathrm{g}^{-1}$, enquanto que o respectivo $\mathrm{q}_{\mathrm{e}}$ calculado foi de $6,89 \mathrm{mg} \cdot \mathrm{g}^{-1}$.

Os resultados demonstram que o mecanismo cinético que melhor representou o processo de adsorção de azul de metileno no precursor estudado foi o de adsorção de pseudossegunda ordem, por apresentar o melhor ajuste aos dados experimentais, bem como os menores desvios entre a quantidade adsorvida calculada e experimental no equilíbrio. Conduzindo a possibilidade de uma adsorção química com possível formação de complexos ou grupos superficiais, ocorrendo devido ao mecanismo de pareamento iônico (Ho e Mckay, 1999). Este mecanismo afeta a possibilidade de reutilização do adsorvente devido a difícil remoção do corante da sua superfície. 


\subsection{Isoterma de adsorção}

As isotermas de adsorção do azul de metileno foram obtidas para avaliar a relação de equilíbrio entre a quantidade de material adsorvido e a concentração na fase fluida, sob temperatura constante. A forma da função da isoterma é determinada pelo mecanismo de adsorção e pode ser usada para sugerir o tipo de adsorção que ocorre entre o adsorvente e o adsorbato.

O equilíbrio de adsorção de azul de metileno foi expresso em termos de isotermas de adsorção, sendo linearizado pelos modelos de Langmuir e Freundlich, conforme Figuras 5 e 6.
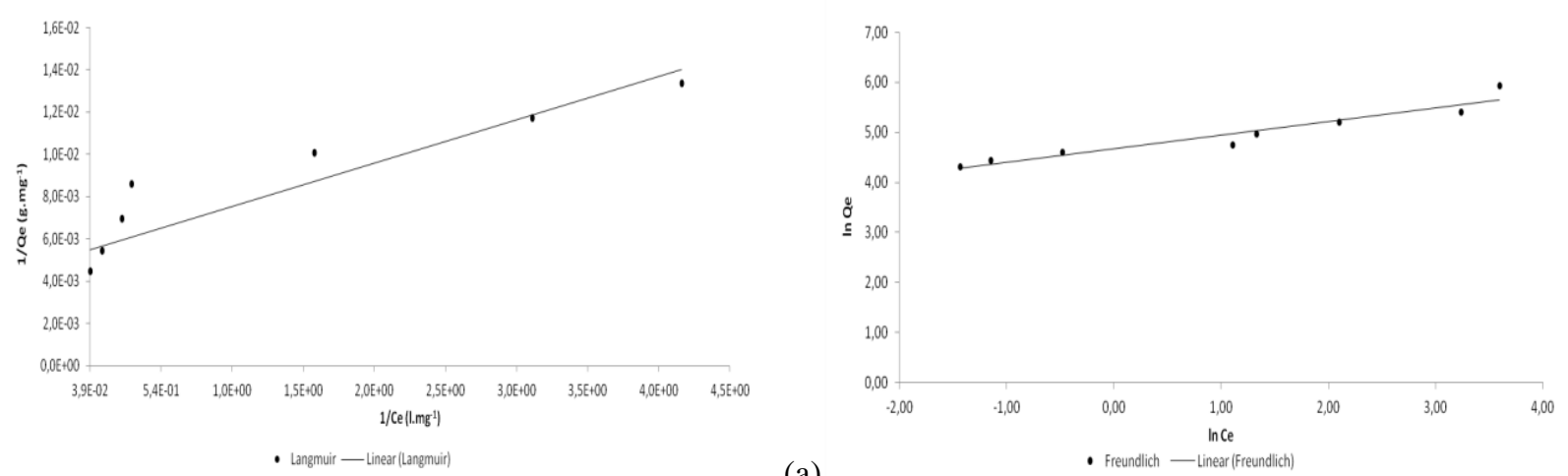

(a)

Figura 5 - Linearizações da isoterma de adsorção para o carvão ativado com ácido fosfórico 1:1 por 1 hora em $\mathrm{pH}_{\text {inicial }}=6,0$. (a) Isoterma de Lagmuir; (b) Isoterma de Freundlich.
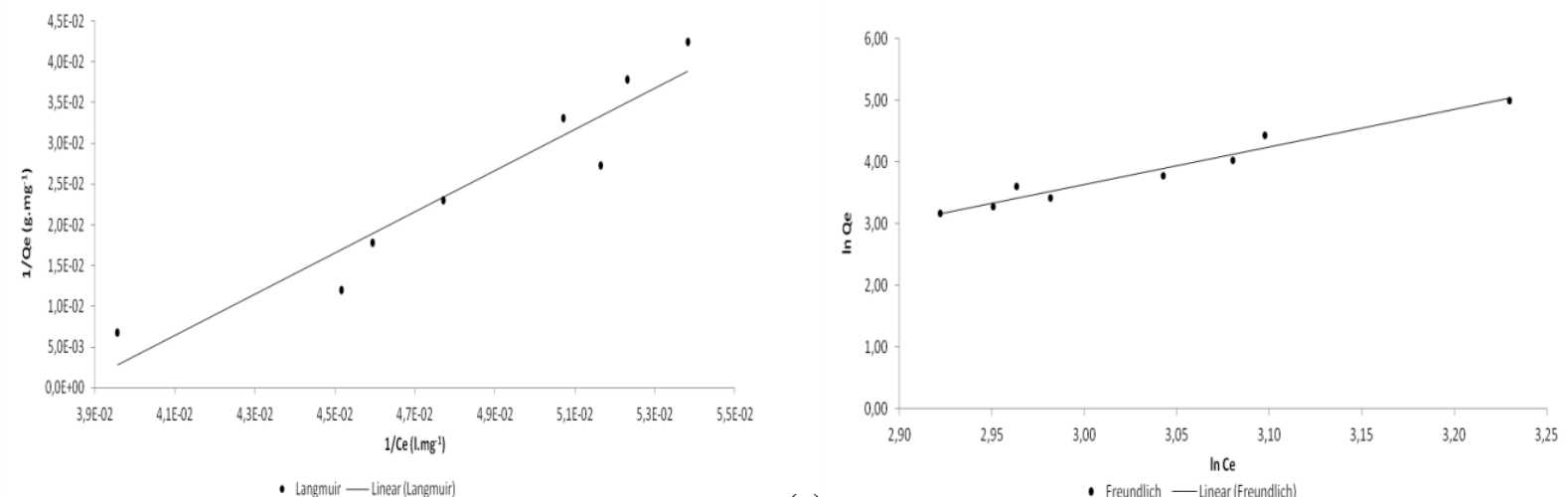

(a)

(b)

Figura 6 - Linearizações da isoterma de adsorção para o carvão carbonizado a $400{ }^{\circ} \mathrm{C} \mathrm{em} \mathrm{pH}_{\text {inicial }}=$ 6,0. (a) Isoterma de Lagmuir; (b) Isoterma de Freundlich.

As análises demonstraram que a isoterma de Freundlich foi o modelo que melhor se ajustou aos dados experimentais, ou seja, a adsorção ocorre por multicamadas, não existindo limite para saturação e sendo possível o completo preenchimento dos poros.

As Tabelas 1 e 2 apresentam os valores para os parâmetros ajustados das isotermas de adsorção de Langmuir e Freundlich para os dois carvões obtidos, respectivamente. 
Tabela 1 - Parâmetros das isotermas de Langmuir e Freundlich para o carvão ativado com ácido fosfórico 1:1 por 1 hora

\begin{tabular}{|c|c|c|c|c|c|c|}
\hline \multicolumn{3}{|c|}{ Langmuir } & \multicolumn{4}{|c|}{ Freundlich } \\
\hline$q_{\max }\left(\mathrm{mg} \mathrm{g}^{-1}\right.$ & $\mathbf{K}\left(\right.$ L.mg $^{-1}$ & $\mathbf{R}^{2}$ & $1 / \mathbf{n}$ & $\mathbf{n}$ & $K_{F}\left(\left(m^{\prime} \cdot g^{-1}\right) \cdot(L \cdot m g-1)^{1 / 1}\right.$ & $\mathbf{R}^{2}$ \\
\hline 185,185 & 2,700 & 0,805 & 0,27 & 3,67 & 107,168 & 0,918 \\
\hline
\end{tabular}

Tabela 2- Parâmetros das isotermas de Langmuir e Freundlich para o carvão carbonizado a $400{ }^{\circ} \mathrm{C}$

\begin{tabular}{|c|c|c|c|c|c|c|}
\hline \multicolumn{3}{|c|}{ As Langmuir } & \multicolumn{4}{|c|}{ Freundlich } \\
\hline$q_{\max }\left(\mathrm{mg} \mathrm{g}^{-1}\right.$ & K (L.mg ${ }^{-1}$ & $\mathbf{R}^{2}$ & $1 / \mathbf{n}$ & $\mathbf{n}$ & $K_{F}\left(\left(m^{\prime} \cdot g^{-1}\right) .(L \cdot m g-1)^{1 /}\right.$ & $\mathbf{R}^{2}$ \\
\hline 10,288 & 0,038 & 0,904 & 6,057 & 0,16 & $4,85 \times 10^{-7}$ & 0,957 \\
\hline
\end{tabular}

As análises gráficas demonstram que a isoterma de Freundlich é adequada para o carvão ativado, sendo tal observação corroborada pelo valor de $n$ entre 1 e 10 , conforme observado por Colpani (2012) em suas pesquisas.

A isoterma de Langmuir não representa de forma adequada o processo, por não considerar as interações laterais atrativas, cargas superficiais e heterogeneidade do carvão ativado quimicamente. No entanto, o precursor somente carbonizado apresentou um valor desfavorável para a isoterma de Freundlich, e um valor de $\mathrm{q}_{\mathrm{e}}$ próximo ao $\mathrm{q}_{\mathrm{máx}}$, o que representa que este carvão possui uma isoterma de adsorção somente em monocamada, como prevê o modelo de Langmuir. Pode-se perceber que nos testes cinéticos este atingiu aproximadamente o limite máximo de adsorção, atingindo uma adsorção no equilíbrio próxima à determinada pela isoterma de Langmuir como sendo máxima.

\section{CONCLUSÕES}

$\mathrm{O}$ adsorvente apresentou as melhores características superficiais quando o processo de ativação ocorreu a $600{ }^{\circ} \mathrm{C}$, com uma razão de ácido fosfórico e água igual a 1:1 e tempo de ativação de 1 hora, corroborado pelas informações morfológicas por MEV.

O modelo cinético que melhor se ajustou aos dados experimentais foi o de pseudossegunda ordem por apresentar o melhor ajuste aos dados experimentais e os menores desvios entre a quantidade adsorvida calculada e experimental no equilíbrio. No entanto, apesar de o melhor ajuste ter sido a isoterma de Freundlich para a amostra C2, os dados encontrados para os coeficientes apresentam uma adsorção desfavorável em multicamadas, levando a conclusão de que este carvão possui adsorção somente em monocamadas, no qual após ser atingida a capacidade máxima não haverá mais adsorção, o que foi verificado durante os testes cinéticos. Os resultados apresentados neste trabalho indicam a casca de banana como um adsorvente alternativo de baixo custo com grande potencial para remoção de azul de metileno e outros corantes catiônicos presentes em corpos d'água e em efluentes.

\section{REFERÊNCIAS}

AGUIAR, M. R. M. P. de; NOVAES, A. C; GUARINO, A. W. S. Remoção de metais pesados de efluentes industriais por aluminossilicatos. Quím. Nova, São Paulo, v. 25, n. 6b, 11451154, 2002. 
ANNADURAI, G.; JUANG, R. S.; LEE, D. J. Use of cellulose-based wastes for adsorptionof dyes from aqueous solutions. J. of Hazard. Mater., B92, pg. 263-274, 2002.

BAKRY, F.; CARREL, F.; CARUANA, M. L.; COTE, F. X.; JENNY, C.; TEZENAS, D. H. Les bananiers. L'ameliorationdesplantestropicales. A. Cherrier et al. Eds., Montpellier, France, CiradOrstom, collection Repères,1997, pp.109-139.

CLARK, H. L. M. Remoção de Fenilalanina por Adsorvente Produzido a partir da Torta Prensada de Grãos Defeituosos de Café. Belo Horizonte: Dissertação de Mestrado. Programa de Pós-Graduação em Ciência de Alimentos da Faculdade de Farmácia da Universidade Federal de Minas Gerais, 2010. 115 p.

COLPANI, G. L. Preparação e caracterização de adsorventes para a remoção de surfactantes aniônicos em águas residuárias. Dissertação de mestrado. Universidade Federal de Santa Catarina, 2012.

DALLAGO, R. M.; SMANIOTTO, A. Resíduos sólidos de curtumes como adsorventes para a remoção de corantes em meio aquoso. Quím. Nova, São Paulo, v.28, n.3, 433-437,2005.

EMBRAPA. Cultivo de Banana em Rondônia. EMBRAPA Rondônia. Sistemas de Produção, 2. Versão Eletrônica Dez. 2005.2 Disponível em: $<$ http://sistemasdeproducao.cnptia.embrapa.br/FontesHTML/Banana/CultivodaBananaRO/index.h tm>. Acesso em: 27 de Outubro de 2012.

FREIRE,F. B.; FREITAS, S. L. de. Avaliação da remoção de cor de um efluente têxtil sintético. Eng. Amb. - Espírito Santo do Pinhal, v. 7, n. 3, jul ./set . 2010.

HO, Y. S.; MCKAY, G. Pseudo-second order model for sorption processes. Process Biochem., v. 34, pg. 451-465, 1999.

JUCHEN, P.T.; GOBI, F. P.; HONORIO, G. C.; GONÇALVES, G. C.; VEIT, M. T. Aplicação do palito de erva-mate como adsorvente no processo de adsorção do corante azul de metileno. Universidade Estadual do Oeste do Paraná, Centro de Engenharias e Ciências Exatas. U T F P, Processos Químicos, Anais do V SEQ, Simpósio de Engenharia Química, Maringá - PR, 2013.

NAHIL, M. A.; WILLIAMS, P. T. Pore Characteristics of Activated Carbons from the Phosphoric Acid Chemical Activation of Cotton Stalks. Biomass and Bioenergy, v. 37, p. 142-149, 2012. 